\title{
Mr Mom: can we deliver?
}

\section{Joanne Li Shen Ooi}

\section{Introduction}

Man's age-old fascination with the idea of male pregnancy is evident from numerous references to it in ancient mythology. Today, in the wake of the in vitro fertilisation (IVF) revolution and other examples of innovative reproductive technology opening up a world of reproductive possibility, the thought of procreation sans female captivates the public consciousness more than ever. Several attempts (both human and non-human) at proving the feasibility of male pregnancy have been documented. The hypothetical process that would be involved in introducing a pregnancy in the man, given our current understanding of reproduction, is in essence analogous to creating an extrauterine pregnancy in the woman, which is itself fraught with risks and complications. There are many reasons behind the demand for feasible extrauterine pregnancy that are explored in this essay, and the psychosomatic phenomenon peculiar to expectant fathers overly sympathetic to their pregnant partners' plight known as 'Couvade syndrome' is discussed at some length. Should man want to keep pursuing the quest for getting men pregnant, we would do well to take a closer look at the only known examples of male mothers in the animal kingdom: seahorses and pipefish. My concluding sentiments are that male pregnancy is definitely a possibility and part of a natural progression in our longstanding challenge of stereotypical gender roles in society.

\section{The world's first pregnant man?}

The video follows the expectant mother getting around New York City in a cab, paying a visit to the doctor for a routine check-up, shopping at the supermarket, glowingly receiving enquiries and congratulations from curious strangers, convincing a non-pregnant bus passenger to give up their seat, and finally strolling off towards the neon-lit horizon of an urban jungle in calm contemplation of what the future holds. Nothing out of the ordinary, except for one significant detail: the mother is a man. In fact, he's "The Pregnant Mr. Lee", Time magazine's "Man(?) of the Year" (Figure 1).

This documentary has been making its rounds on the Internet since 1999, yet 10 years on you can still log onto Lee Mingwei's website (www.malepregnancy.com) ${ }^{1}$ and monitor the progress of the never-ending pregnancy by looking at his ECGs, ultrasounds and "other vitals", purportedly being fed online live under the care of the RYT Hospital - Dwayne Medical Center, the team that organised the Phase II clinical trial that made Lee the world's "first pregnant man". It's one medical first that has yet to be reported in any medical journal, and no stork is expected at the Lee residence any time soon. That's right - it's all an elaborate hoax.

\section{A fertile imagination}

The idea of male pregnancy is by no means an original one. Zeus, king of the Greek gods, had his head split open by Hephaestus the blacksmith in order to 'give birth' to a fully-

J Fam Plann Reprod Health Care 2009; 35(1): 56-58

(Accepted 4 July 2008)

King's College London School of Medicine, London, UK Joanne Li Shen Ooi, DHMSA, Medical Student

Correspondence to: Ms Joanne Li Shen Ooi.

E-mail: joanne.ooi@kcl.ac.uk armed Athena; sewn into Zeus' thigh was the womb from which a fetal Dionysus was born. In Norse legend, Loki the shape-shifter bears a foal after morphing into a beautiful mare to seduce a stallion. The sacred Hindu Veda texts describe Lord Brahma being brought into the world within a lotus that blooms forth from Lord Vishnu's umbilicus like an external womb.

In the mid-1990s, popular culture witnessed a resurgence in interest in male pregnancy. This was spearheaded by the 1994 film, Junior, which featured Arnold Schwarzenegger waddling around in a pink maternity dress after impregnating himself in the name of medical research. Stanley Pottinger's novel, The Fourth Procedure, features a female transplant surgeon who surreptitiously implants a fetus into the belly of the Chief Justice of the US Supreme Court in an attempt to change his conservative views on abortion. A more recent example is actor David Duchovny, who allegedly walked out of discussions over the plotline of an $X$ Files season cliffhanger when it was suggested that Mulder should fall pregnant after being contaminated with alien DNA.

Mere speculation or tomorrow's science? Scientists have certainly tried to make male pregnancy happen, at least in primates. In the 1960s, one Chinese doctor claimed to have induced pregnancy in a chimpanzee but had his laboratory - and all evidence of the experiment destroyed by Cultural Revolution zealots. Around the same time an American fertility doctor, Cecil Jacobson, declared that he had successfully implanted a baboon embryo in a male baboon but aborted it after 4 months. ${ }^{2}$ Whether or not these actually happened, a whole can of worms has been opened. What about humans? When will the world see the

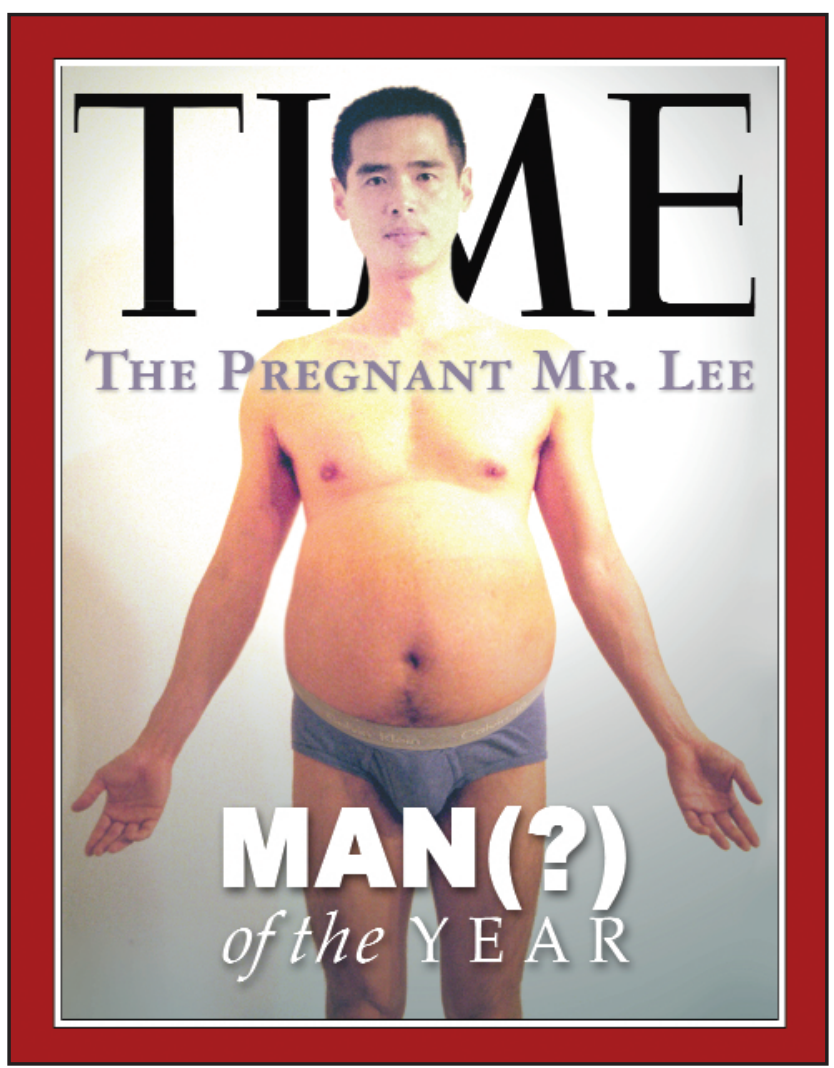

Figure 1 Going where no man has ever been before... a pregnant Lee Mingwei on the cover of Time magazine ${ }^{1}$ 
first pregnant man? Aren't real men, you know, lacking an absolutely crucial something - a womb.

\section{'Men' who have a womb}

In fact some men do have wombs. This is true of 'transmen' - transgender people originally assigned the female gender at birth but who have subsequently legally identified themselves as male - who have not completed the full process of gender reassignment.

And in fact depending on how strict your definition of a 'man' is, the world has already seen its first pregnant men. Transman Matt Rice of Hawaii stopped taking his testosterone, underwent artificial insemination and gave birth to a boy in 2000 before having a hysterectomy to complete the transition to becoming a man. ${ }^{3}$ The leading gay publication in the USA, The Advocate, ran a story written by another transman, Thomas Beatie, who has chosen to conceive and carry a child by the same means because his wife had had her uterus removed; he is due to deliver in July 2008.4 [Author note added in proof: Since this essay was written, Thomas Beatie has given birth to a healthy baby girl on 29 June 2008. Both the 'mothers' and baby are reportedly doing well.]

\section{Pushing the envelope}

But to return to the original question of whether 'real' men (who are genetically and physiologically fully male) can bear children: the answer is 'not yet'. Male pregnancy would certainly be a biologically impossible event under traditional circumstances, but a number of scientists have speculated on the possibilities.

Lord Robert Winston, Professor of Fertility Studies at Imperial College London, UK, sparked considerable controversy in 1999 when he told The Sunday Times that "male pregnancy would certainly be possible". 5

But while it is safe to say that the scientific community as a whole agrees with the theoretical possibility of male pregnancy, they also concede that the process would be complicated and even potentially fatal. For with our current understanding of reproduction, the proposed male pregnancy would have to be, in essence, an extrauterine pregnancy: a phenomenon known to be fraught with risk to mother (or father) and baby.

The specifics of the procedure go like this: first, the male body needs to be chemically primed for motherhood. A doctor would administer a battery of exogenous estrogens, progestogens and fertility drugs, the same hormone cocktail received by postmenopausal women hoping to conceive using donor eggs. Likely side effects include gynaecomastia, sterility and even cancer, not to mention the 'emotional rollercoaster' oft-attributed to female hormones, namely premenstrual syndrome (PMS). Imagine a man having PMS for 9 months!

The gender of the child would be predetermined inevitably male - otherwise the necessary hormone injections to produce a female fetus would effectively 'castrate' or feminise the male host - thus ostensibly defeating the purpose of inducing pregnancy in, well, men.

Next comes impregnation itself. This would involve the laparoscopic implantation of the embryo, produced by IVF, and a placenta in the man's abdomen. The obvious question here would be where in the abdomen. While a substitute for the womb has yet to be discovered, after studying the not too uncommon examples of viable extrauterine pregnancies in females (the estimated incidence of abdominal pregnancies is 1 in 10000 or $1 \%$ of all ectopic pregnancies ${ }^{6}$ ), experts have proposed the greater omentum, hanging like an apron in front of the intestines, as an ideal alternative site. The fertilised egg is in essence a parasite. All it needs for implantation is a rich blood supply to tap into, as a number of women posthysterectomy have found out to their great surprise.

After implantation, the male would no longer need to take estrogens since the embryo would secrete sufficient hormones to sustain its own growth. The pregnancy would be left to run its own course, analogous to any ectopic female pregnancy; however, cases of the latter do tend to get aborted immediately after diagnosis, as they are fraught with risk to both mother and fetus. A ruptured ectopic pregnancy is a genuine medical emergency and is the leading cause of maternal mortality in the first trimester, accounting for $10-15 \%$ of all maternal deaths. ${ }^{7}$ Perinatal mortality has been reported at $85-95 \%$; the maternal mortality rate is about $6 \% .8,9$ Only one-quarter of all extrauterine pregnancies that make it to the mid-trimester will be viable, and only half of those survive past 1 week postpartum. ${ }^{10}$ In other words, a male pregnancy is not one that is expected to run smoothly.

If our hypothetical fetus beats the odds and comes to term, a Caesarean section or other laparotomic procedure would be necessary. And therein lies the most pernicious danger to the man. The uterus is designed to cope with the 8inch wound left when the placenta separates by contracting around itself ('involuting') to prevent haemorrhage; other organs do not possess such a mechanism, and if not dealt with by highly experienced obstetricians, the resultant hypovolaemic shock could well lead to death. The alternative option - leaving the placenta inside the abdominal cavity to be reabsorbed after severing the umbilical cord - would entail a high chance of infection due to tissue necrosis.

Nor is the baby at all free from risk. Oligohydramnios is a common feature of extrauterine pregnancy; that plus the lack of the protective environment of a proper uterus would render the fetus susceptible to abnormal, teratological moulding forces inside the peritoneal cavity from abdominal organs and pelvic structures. This would give rise to a long list of anatomical deformities suffered by $75 \%$ of babies that survive extrauterine pregnancies: facial asymmetry, plagiocephaly, torticollis, neck webbing, chest wall malformations, talipes, multiple joint contractures, congenital dislocation of the hip, and so on. And these are just the more easily managed deformities: more severe malformations have included pulmonary hypoplasia, myelomeningocele, ectromelia, complete absence of the lower limbs, microcephaly with cerebral palsy, and absence of the mouth, arms and eyes. 8,10

And it goes without saying that preterm labour would be exceedingly likely given the unconventional circumstances surrounding the fetus' gestation, thus further increasing perinatal mortality and morbidity.

Why would any man want to get pregnant? Despite all its potential perils, the idea of male pregnancy continues to intrigue the public consciousness for many reasons. It holds obvious appeal for gay (or single) men since it eliminates the need for surrogate mothers to carry their own biological children. In his book The IVF Revolution, ${ }^{11}$ Lord Winston argues the case for introducing reasonably safe ectopic pregnancies (once that is possible) in 'transwomen' - the opposite of the 'transmen' discussed earlier in this essay. This would allow these women who carry a Y chromosome and not a uterus, but who possess normal female gender identity and sexuality, to conquer the dispossession that comes with their presumed 'sterility'.

Heterosexual couples also stand to benefit since this technique would provide yet another option for overcoming infertility in the female, or her inability to carry pregnancies to term for other medical or psychological reasons. From a father-to-be's perspective, one bonus of male pregnancy is 
his complete confidence in paternity. Partners who are healthy and able from a reproductive standpoint can share not just childrearing but also childbearing duties. It is easy to imagine feminists everywhere hailing male pregnancy as the ultimate triumph in women's liberation. It could even lead to a reversal of age-old stereotypical gender roles - suddenly threats of "You try being pregnant!" from fed-up wives to unsympathetic husbands would no longer ring so hollow.

\section{"I feel your pain"}

But of course not all men are unsympathetic. In fact one or two have been known to go to extreme lengths to empathise with their expectant wives, one example being London journalist, Adrian Gatton, who set out to recreate the fullblown pregnant experience by wearing a special belly, ankle weights and nipple pegs. He also made an effort to bring his insides in line with that of his pregnant partner by "eating baked beans to increase flatulence and drinking salt water each morning to be sick". ${ }^{2}$

Up to this point in time, the best natural approximation men have had available to the trials and tribulations of 'male pregnancy' has been Couvade syndrome (the name is derived from the French verb couver, 'to hatch'), a curious psychosomatic condition affecting roughly $11 \%$ of expectant fathers. These young men, usually first-time fathers, experience a range of symptoms, including cramps, back pain, mood swings, food cravings, morning sickness, fatigue, depression, fainting, insomnia and toothache. Less frequently, men develop abdominal swelling similar to 'baby bumps'. These symptoms tend to resolve after the baby's delivery. ${ }^{13}$

Also known colloquially as 'phantom pregnancy', Couvade syndrome has been well-documented in a number of cultures in Africa and Australasia (e.g. the Logoli people of Kenya and the Hua of Papua New Guinea). ${ }^{14,15}$ Considerable academic interest in the phenomenon in the mid-20th century gave rise to some very interesting literature that explored possible underlying psychosexual theories. More recently, studies have also been conducted in developed countries proving the prevalence of Couvade syndrome in Western societies and therefore the universality of this syndrome. Dr Arthur Brennan of St George's Hospital, London, UK, who co-authored a study of 282 fathers-to-be in $2007,{ }^{16}$ commented of his subjects that "these men were so attuned to their partners, they started to develop the same symptoms". 17

Still poorly understood, the phenomenon was initially attributed to any number of hypotheses including 'somatised anxiety', 'parturition envy', sex-identity conflicts, complex paternal-fetal attachments or just fathers 'trying to get in on the act' ${ }^{14-16,18}$ It is now known that the symptomatology is largely involuntary and could be due to hormonal fluctuations as the due date draws near.

\section{Not such a fishy idea}

While true human male pregnancy remains relegated to 'what if' entertainment, the broody man can take heart in the success of his seahorse and pipefish counterparts: the Syngnathidae family to which these two species belong is the only one in the animal kingdom to which the term 'male pregnancy' has been accurately applied. ${ }^{19}$ During mating, a female uses an ovipositor to transfer unfertilised eggs to the underside of a male in brood sacs (reminiscent of female kangaroo pouches), where he then broods and nourishes the embryos. The male continues to provides all post-zygotic care of the offspring until they become independent young adults. $^{20}$

Current research suggests compelling morphological and functional similarities between the mammalian reproductive model and that of syngnathid mating systems. Perhaps before rushing to introduce unquestionably unsafe ectopic pregnancies in men, it might be worth devoting more energy towards the study of these little aquatic organisms, for they have the potential to afford us disproportionately large insights into the process of male maternity. ${ }^{19,20}$

\section{Conclusion: a pregnant pause...}

Male pregnancy looks like a definite maybe, given the demand for it and its theoretical feasibility. Barring all the ethical and clinical controversy that is bound to arise, if we get the technology right then nature might just warm to the idea of male moms after all.

The world's first pregnant man/hoax artist $\mathrm{Mr}$ Lee perhaps explains it best when he says: "Why shouldn't a man bear the same burden that women have always carried? On the other hand, why shouldn't a man be able to experience the same joy and excitement that a woman feels nurturing within her own body? Now I think men, as well as women, have more choices, more possibilities, more roles they can assume in their lives."1

\section{Acknowledgements}

The author would like to thank her parents and Mr Tarek El-Toukhy, Subspecialty Registrar in Reproductive Medicine at Guy's \& St Thomas' NHS Foundation Trust, for providing inspiration for this essay.

\section{Statements on funding and competing interests \\ Funding None identified. \\ Competing interests None identified.}

References

1 Lee M. POP! The First Human Male Pregnancy. http://www.malepregnancy.com [Accessed 14 March 2008].

2 Andrews L. Opinion: Mister Mom: not just after birth anymore. Male pregnancy is the future. The Daily Princetonian, 8 May 2002

3 Califia-Rice P. Two dads with a difference - neither of us was born male. The Village Voice, 20 June 2000.

4 Beatie T. Labor of Love: is society ready for this pregnant husband? The Advocate, 8 April 2008.

5 Goddard A. Fertile with ideas for the infertile. Times Higher Education, 14 May 1999.

6 Moonen-Delarue MW, Haest JW. Ectopic pregnancy three times in line of which two advanced abdominal pregnancies. Eur $J$ Obstet Gynecol Reprod Biol 1996; 66: 87-88.

7 Centers for Disease Control and Prevention. Ectopic pregnancy United States, 1990-1992. JAMA 1995; 273: 533.

8 Uglow MG, Clarke NM. Congenital dislocation of the hip in extrauterine pregnancy. J Bone Joint Surg Br 1996; 78: 751-753.

9 Beacham WD, Hernquist WC, Beacham DW, Webster HD. Abdominal pregnancy at Charity Hospital in New Orleans. Am J Obstet Gynecol 1962; 84: 1257-1270.

10 Golan A, Sandbank O, Andronikou A, Rubin A. Advanced extrauterine pregnancy. Acta Obstet Gynecol Scand 1985; 64: 21-25.

11 Winston RML. The IVF Revolution: The Definitive Guide to Assisted Reproduction Techniques. London, UK: Vermillon, 1999.

12 Gatton A. Man's first virtual pregnancy. BBC News Health, 27 August 1999. http://news.bbc.co.uk/1/hi/health/432011.stm [Accessed 14 March 2008].

13 Gelder MG, Lotus Ibor JJ, Andreasen NC. New Oxford Textbook of Psychiatry. Oxford, UK: Oxford University Press, 2000.

14 Munroe RL, Munroe RH, Nerlove SB. Male pregnancy symptoms and cross-sex identity: two replications. J Soc Psychol 1973; 89: $147-148$

15 Munroe RL, Munroe RH. Male pregnancy symptoms and crosssex identity in three societies. J Soc Psychol 1971; 84: 11-25

16 Brennan A, Marshall-Lucette S, Ayers S, Ahmed H. A qualitative exploration of the Couvade syndrome in expectant fathers. $J$ Reprod Infant Psychol 2007; 25: 18-39.

17 Men suffer from phantom pregnancy. BBC News Health, 14 June 2007. http://news.bbc.co.uk/1/hi/health/6751709.stm [Accessed 14 March 2008].

18 Schodt CM. Parental-fetal attachment and couvade: a study of patterns of human-environment integrality. Nurs Sci Q 1989; 2: 88-97.

19 Jones AG, Avise JC. Microsatellite analysis of maternity and the mating system in the Gulf pipefish Syngnathus scovelli, a species with male pregnancy and sex-role reversal. Mol Ecol 1997; 6: 203-213.

20 Stolting KN, Wilson AB. Male pregnancy in seahorses and pipefish: beyond the mammalian model. Bioessays 2007; 29: 884-896. 